\title{
A baseline probabilistic drought forecasting framework using standardized soil moisture index: application to the 2012 United States drought
}

\author{
A. AghaKouchak \\ Center for Hydrometeorology and Remote Sensing, Department of Civil and Environmental Engineering, \\ University of California, Irvine, CA, USA
}

Correspondence to: A. AghaKouchak (amir.a@uci.edu)

Received: 28 January 2014 - Published in Hydrol. Earth Syst. Sci. Discuss.: 11 February 2014

Revised: 9 May 2014 - Accepted: 21 May 2014 - Published: 4 July 2014

\begin{abstract}
The 2012 drought was one of the most extensive drought events in half a century, resulting in over USD 12 billion in economic loss in the United States and substantial indirect impacts on global food security and commodity prices. An important feature of the 2012 drought was rapid development and intensification in late spring/early summer, a critical time for crop development and investment planning. Drought prediction remains a major challenge because dynamical precipitation forecasts are highly uncertain, and their prediction skill is low. Using a probabilistic framework for drought forecasting based on the persistence property of accumulated soil moisture, this paper shows that the US drought of summer 2012 was predictable several months in advance. The presented drought forecasting framework provides the probability occurrence of drought based on climatology and near-past observations of soil moisture. The results indicate that soil moisture exhibits higher persistence than precipitation, and hence improves drought predictability.
\end{abstract}

\section{Introduction}

According to United States Department of Agriculture (USDA) estimates, about 80 percent of US agricultural land experienced drought in 2012, which made the event more extensive than any since 1950 (USDA, 2012). A striking aspect of the 2012 drought was rapid increase in severity in early July during a critical time of crop development (USDA, 2012). The quick onset of the drought in the central plains during late spring led to a so-called "flash drought" (Hoerling et al., 2013, 2014). A drought early warning system with seasonal predictions of drought onset, severity, persistence, and spatial extent in a timely manner would provide invaluable information to decision-makers and stakeholders. There are a number of research and operational drought (or hydrologic) prediction systems (Pozzi et al., 2013; Mishra and Singh, 2010; AghaKouchak and Nakhjiri, 2012), including the Climate Prediction Center Seasonal Drought Outlook (Steinemann, 2006), the University of Washington's Surface Water Monitor (Wood and Lettenmaier, 2006; Wood, 2008), Princeton University's drought forecast system (Luo and Wood, 2007; Li et al., 2008; Sheffield et al., 2008), USMexico Drought Prediction Tool (Lyon et al., 2012), and the Global Integrated Drought Monitoring and Prediction System (GIDMaPS; Hao et al., 2014). Despite all these efforts, a community white paper by the World Climate Research Program identified sub-seasonal to seasonal drought prediction as one of the major research gaps in hydroclimatology (WCRP, 2010).

Drought forecasting is generally based on drought indicators computed using dynamic or statistical model simulations of drought-related variables (e.g., Mishra et al., 2009; Madadgar, and Moradkhani, 2013). Droughts are classified as agricultural (soil moisture deficit), meteorological (precipitation deficit), and hydrological (streamflow/groundwater deficit), and various drought indicators based on soil moisture, precipitation and runoff have been developed to describe different aspects of droughts (Heim, 2002; Wood et al., 2002; Wood and Lettenmaier, 2006; Mo, 2008; Shukla and Lettenmaier, 2011; Hao and AghaKouchak, 2013). Most drought prediction studies are based on the standardized precipitation index (SPI; McKee et al., 1993) with the input precipitation derived from dynamical weather/climate models 
(Yoon et al., 2012; Mwangi et al., 2014; Dutra et al., 2013, 2014a, b). While dynamic models provide valuable information, precipitation forecasts are subject to high uncertainty and models exhibit very low skill in predicting precipitation with a few months lead time (Goddard et al., 2003; National Research Council, 2006; Livezey and Timofeyeva, 2008; Lavers et al., 2009). A baseline probability method is proposed for meteorological drought forecasting based on persistence of the SPI (Lyon et al., 2012), indicating that a statistical persistence-based model could lead to a good seasonal drought forecasting skill (Quan et al., 2012). Hao et al. (2014) developed a multivariate method for statistical drought prediction using a persistence-based approach.

Soil moisture is often used as an indicator of agricultural drought monitoring, and has been used in different forms (Samaniego et al., 2013) including the soil moisture percentile (Luo and Wood, 2007; Wood, 2008; Shukla et al., 2011), normalized soil moisture (Dutra et al., 2008), and soil moisture anomaly (Sheffield and Wood, 2007; Sheffield and Wood, 2008). Typically, precipitation and temperature forecasts, either from dynamic models or climatology resampling (i.e., ensemble streamflow prediction, ESP method; Mo et al., 2012), are used to force land-surface/hydrologic models for predicting soil moisture conditions and drought (e.g., Luo and Wood, 2007; Luo and Wood, 2008; Trambauer et al., 2013). The uncertainty of dynamic soil moisture forecasts is even higher than the climate forcings (precipitation and temperature) because, in addition to input uncertainty, model errors and uncertainty also propagate into soil moisture simulations. For this reason, different statistical methods such as conditional ESP resampling have been explored for soil moisture prediction (Wood, 2008).

Persistence is a distinctive characteristic of the soil moisture as it exhibits less variability relative to precipitation (Hao and AghaKouchak, 2014). Mo et al. (2012) emphasized the importance of the persistence of soil moisture in improving drought forecasting skill. Great strides have been made to explore soil moisture persistence properties, and results reveal that the persistence of soil moisture memory spans weeks to a couple of months (Vinnikov and Yeserkepova, 1991; Entin et al., 2000; Seneviratne et al., 2006; Koster et al., 2010). Though the persistence property of soil moisture has been well documented, the properties of accumulated soil moisture and its potential use for drought forecasting have not been investigated as thoroughly. In this study, a probabilistic drought prediction framework is proposed using the standardized soil moisture index (SSI) as the drought indicator, which allows for the description of soil moisture across different timescales (e.g., 3, 6, and 12 months). In other words, soil moisture is treated in a similar fashion to precipitation accumulation across different timescales relative to the corresponding long-term climatology (McKee et al., 1993). Given the temporal integration of data, SSI leads to even higher persistence compared with the commonly used soil moisture percentiles or soil moisture anomaly.

\section{Data}

The data sets used in this study include the monthly precipitation and soil moisture from the NASA Modern-Era Retrospective analysis for Research and Applications (MERRALand), available on a $2 / 3^{\circ} \times 1 / 2^{\circ}$ grid from 1 January 1980 onwards (Reichle et al., 2011; Rienecker et al., 2011). MERRA data sets have been used in numerous studies in different climatic regions (Bosilovich et al., 2011; Golian et al., 2014; Wong et al., 2011). Uncertainties in MERRA data sets have been evaluated against different observations (e.g., Yi et al., 2011; Kennedy et al., 2011). The results show that MERRA provides valuable information consistent with observations especially in the midlatitudes, while uncertainties in high latitudes are often large (Yi et al., 2011; Reichle et al., 2011).

\section{Methodology}

The standardized soil moisture index (SSI; Hao and AghaKouchak, 2014) can be defined in a similar way to the commonly used standardized precipitation index (SPI; Mckee et al., 1993) that has been used in a wide variety of studies (Dutra et al., 2013; Damberg and AghaKouchak, 2013). Here, the SSI is estimated using a nonparametric approach in which the empirical probability $(p)$ of the historical soil moisture data is derived using the empirical Gringorten plotting position (Gringorten, 1963). In other words, instead of fitting a distribution function to soil moisture data, the probabilities $(p)$ are obtained empirically using the empirical Gringorten approach: $(i-0.44) /(n+0.12)$, where $n$ denotes the sample size and $i$ refers to the rank of soil moisture data from the smallest to the largest.

The empirical probabilities, derived from the Gringorten plotting position, are then transformed into the standard normal distribution function: $\mathrm{SSI}=\Phi^{-1}(p)$, where $\Phi$ is the standard normal distribution function. In this approach, one can avoid making a decision about the parametric distribution function of accumulated soil moisture at different timescales. Assume that soil moisture for the month $i$ is $S_{i}$. Then the 6month accumulation of the soil moisture $A_{i}$ for the month $i$ can be expressed as (Hao et al., 2014)

$A_{i}=S_{i-5}+S_{i-4}+S_{i-3}+S_{i-2}+S_{i-1}+S_{i}$.

In this study, the ensemble streamflow prediction (ESP) method (Twedt et al., 1977; Day, 1985) is used for resampling from historical records of soil moisture to obtain monthly moisture at the target season with the 6-month SSI as the drought indicator. Assume the $l$-month lead forecasting is needed based on the monthly soil moisture observations with forecast initialization at month $i$. Then the $l$ month $(1 \leq l \leq 5)$ ahead forecasting of the accumulated soil moisture $A_{i+l}$ can be expressed:

$A_{i+l}=S_{i+l-5}+S_{i+l-4}+S_{i+l-3}+S_{i+l-2}+S_{i+l-1}+S_{i+l}$. 
Assume that 1-month lead forecasting (i.e., $l=1$ ) based on the 6-month SSI is needed. The unknown $S_{i+1}$ is predicted by resampling the soil moisture from the historical record of the target month (i.e., $i+1$ ). As a result, an ensemble of $m$ (i.e., the length of observation in the historical record) sequence of the monthly soil moisture in the target season can be obtained from the observed monthly soil moisture. In this manner, $m$ sequences of accumulated 6-month soil moisture for the $l$ month lead time can be generated by blending the observed and predicted monthly soil moisture. For example, for $l=1$, the blended sequences of accumulated 6-month soil moisture can be expressed as (Hao et al., 2014)

$A_{i+1}^{(1)}=S_{i-4}+S_{i-3}+S_{i-2}+S_{i-1}+S_{i}+S_{i+1}^{(1)}$,

$A_{i+1}^{(2)}=S_{i-4}+S_{i-3}+S_{i-2}+S_{i-1}+S_{i}+S_{i+1}^{(2)}$,

$\ldots$,

$A_{i+1}^{(m)}=S_{i-4}+S_{i-3}+S_{i-2}+S_{i-1}+S_{i}+S_{i+1}^{(m)}$,

where $S_{i-4}, \ldots, S_{i}$ are the observed soil moisture prior to the target month in the 6-month window, while $S_{i+1}^{(1)}, \ldots, S_{i+1}^{(m)}$ are the sequences of sampled monthly soil moisture from the observations in the historical record for the target month (here, $S_{i+1}$ ). For any timescale (sc) and lead time (l), Eq. (3) can be generalized as

$A_{i+l}^{(1, \ldots, m)}=\sum_{j=0}^{\mathrm{sc}-l-1} S_{i-j}+\sum_{k=1}^{l} S_{i+k}^{(1, \ldots, m)}$.

Note that the lead time $(l)$ should be less than the timescale (sc) - here, 6 months. Each sequence of the blended 6-month soil moisture $A^{(j)}, j=1,2, \ldots, m$ in Eq. (3) can be combined with the observed 6-month accumulated soil moisture in the past years to derive the corresponding $\mathrm{SSI}^{(j)}$. Here, the probability of drought is defined as the probability that a future drought condition (SSI) is lower than an alarm threshold (e.g., SSI $<-0.8$ corresponding to $\sim 20$ th percentile). The empirical probability is estimated by dividing the number of the forecasted values below the threshold (e.g., -0.8 ) by the number of the ensemble members.

\section{Results}

First it is shown that the accumulated soil moisture typically exhibits much higher persistence compared to precipitation, and hence can be used for drought forecasting with up to several months lead time. Then, the 2012 summer drought conditions are predicted using the SSI with different lead times. The SSI is obtained using predicted soil moisture information using the ESP concept based on long-term climatology and near-past observations (see Sect. 3). The study focuses on the drought prediction for May-August, which is an important period for agricultural decision-making.

Understanding the persistence property of soil moisture is fundamental to drought forecasting. It is hypothesized that using accumulated soil moisture would improve persistencebased drought forecasting relative to using accumulated precipitation. First, the persistence property of accumulated soil moisture is evaluated against the accumulated precipitation that has been used for meteorological drought prediction (Lyon et al., 2012; Quan et al., 2012; Hao et al., 2014; Yoon et al., 2012). The monthly precipitation and soil moisture data from MERRA-Land (Reichle et al., 2011; Rienecker et al., 2011) in California and Texas are used to examine the persistence of accumulated soil moisture relative to precipitation. Both states are among the most important producers of agricultural products, and have experienced severe/extreme drought conditions in the past decade. The autocorrelations of accumulated 6-month precipitation and soil moisture for 1-6-month time lags and four different initial conditions (March, April, May and June) for summer drought prediction are provided in Fig. 1. In the figure, the term initial is defined as similar to initial conditions in the Methodology section. For example, March corresponds to precipitation and soil moisture from October 2011 through March 2012. The box plots present the median, 25th, 75th percentiles, and whiskers of the autocorrelations. Lyon et al. (2012) showed that variance of the accumulated precipitation can enhance or diminish the persistence of the SPI at different start times, mainly due to seasonality of precipitation. As shown, the autocorrelation of the accumulated soil moisture (or SSI) is generally higher than that of accumulated precipitation (or SPI) for the four different initial conditions. The figure shows that the autocorrelations of the accumulated 6-month soil moisture decay at a slower rate than the accumulated 6-month precipitation in both California (Fig. 1a) and Texas (Fig. 1b). For example, in California and for the initial condition in April, the medians of the autocorrelation coefficients are higher than 0.6 even at a 5-month lag. However, the medians of the autocorrelations of the 6-month SPI drop below 0.6 after a 4 month lag. The higher persistence of the SSI relative to SPI implies that a persistence-based model based on SSI would lead to better predications as compared to a similar model based on SPI (see also Changnon Jr., 1987).

The 6-month SSI is used as the drought indicator to monitor and predict the 2012 (May-August) US drought. Figure 2a shows observed drought conditions from May to $\mathrm{Au}-$ gust 2012. As shown, the drought develops and intensifies quickly, affecting most of the continental US including the Great Plains, the Midwest, and west and southeast. By August, a large portion of the country experienced severe, extreme, or exceptional drought conditions. In operational drought early warning, the severe drought condition is of critical concern. In this paper, the proposed methodology is tested for predicting the moderate and severe drought conditions in summer 2012. Following the US Drought Monitor (USDM), D-scale, the moderate drought is defined as SSI below -0.8 (corresponding to nonexceedance probability of $\sim 0.2$ ), whereas the severe drought is defined as SSI below -1.3 (or nonexceedance probability of $\sim 0.1$ ) (Svoboda et 
(a)

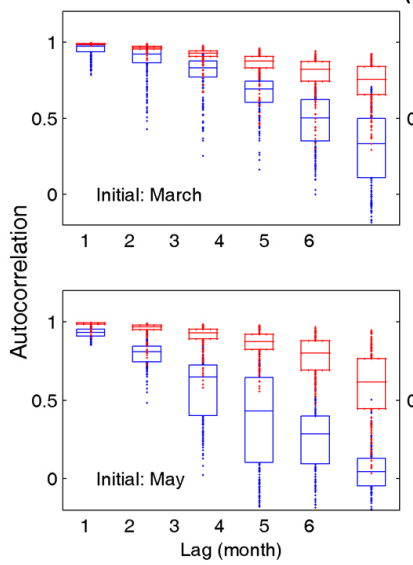

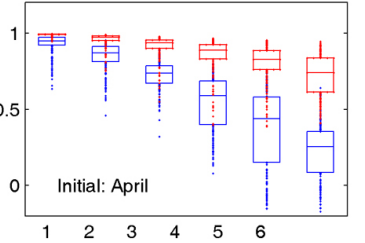

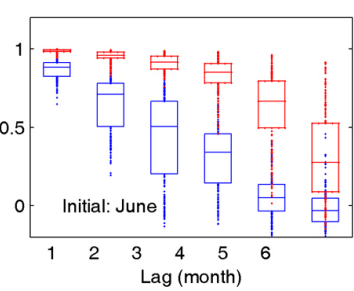

(b)

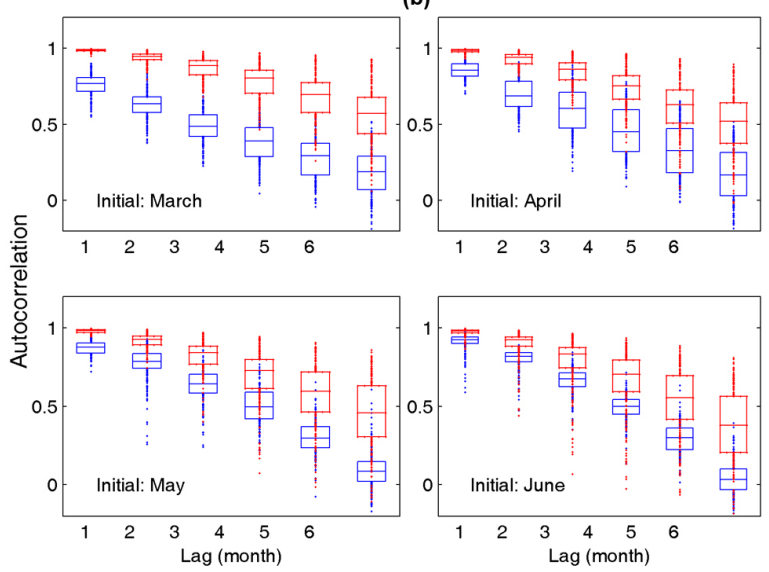

Figure 1. Box plots of autocorrelation coefficients (up to 6 months) of accumulated 6-month precipitation (blue) and soil moisture (red) from MERRA-Land for different initial month for (a) California and (b) Texas. The box plots show the median (center), 25th (lower) and 75th (upper) percentile edges.
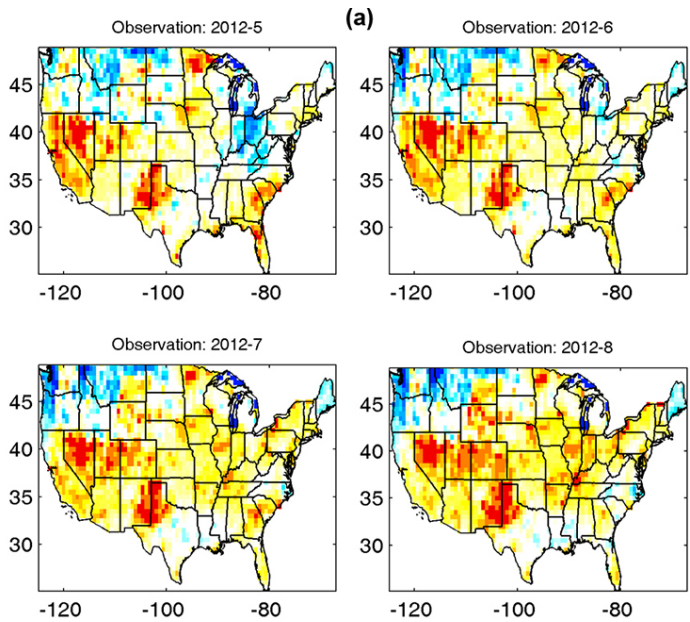

(a)

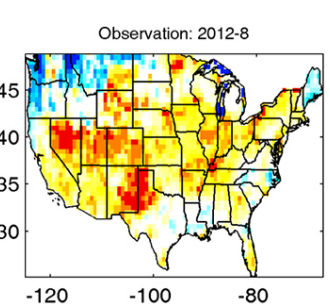

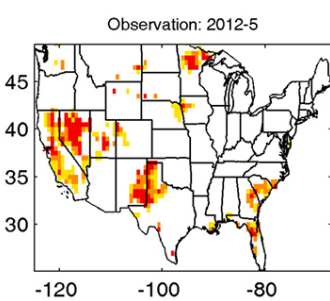

(b)

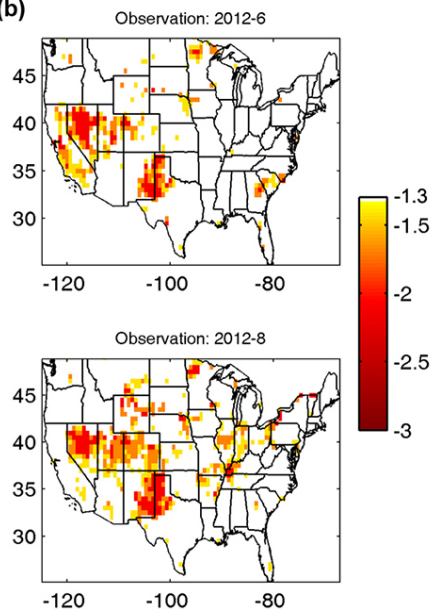

Figure 2. (a) Observed 6-month SSI for May-August 2012; (b) observed 6-month SSI with severe drought condition (SSI $<-1.3$ ) for May-August 2012.

al., 2002). The observed drought conditions below the severe level (D2) for May-August are shown in Fig. 2b.

The 1- and 2-month lead drought (SSI $<-0.8$ ) forecasts for May-August 2012 are presented in Fig. 3a and b, respectively. The 1-month lead forecasted SSI maps for different initializations resemble the observed SSI well in terms of the spatial extent (compare Fig. 3a with Fig. 2a). As shown, the regions with high probability of drought (e.g., above approx. $90 \%$ ) are in very good agreement with the observations. For example, the outlined methodology predicts high probability of drought over the western US and high plains in August, which is consistent with observations. Furthermore, as the 2012 drought intensifies, the area with high probability of drought (Fig. 3a) increases in a similar manner to the observations (Fig. 2a). A visual comparison of the 2-month lead drought forecasts (Fig. 3b) and observations (Fig. 2a) reveals that the predicted drought conditions are in very good agreement with probabilities higher than 0.8 in most regions. The 1 -month and 2-month lead severe drought (SSI $<-1.3$ ) forecasts for May-August 2012 are presented in Fig. 4a and b. The 1-month lead forecasts of May-August severe drought conditions are in very good agreement with observations. As shown, the severe drought conditions from May-August in northern Texas and the western US are captured in the predictions. Figure $4 \mathrm{~b}$ highlights that, even at a 2-month lead, the proposed model predicts the 2012 summer drought reasonably well.

The predicted drought probability maps for July and August 2012 for 3-month and 4-month lead time are presented in Fig. 5a (SSI $<-0.8)$ and $\mathrm{b}(\mathrm{SSI}<-1.3)$. One can see that the 3-and 4-month lead forecasts capture the observed drought conditions with probabilities ranging from 0.1 to 0.8 . 


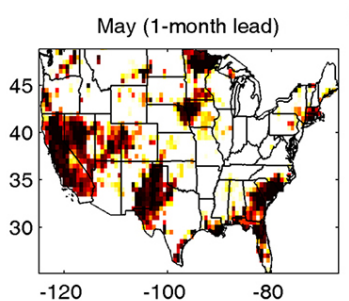

(a)

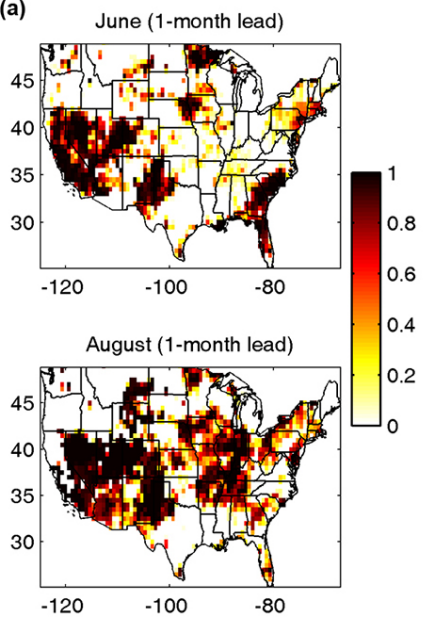

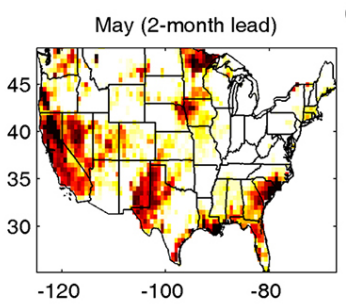

(b)
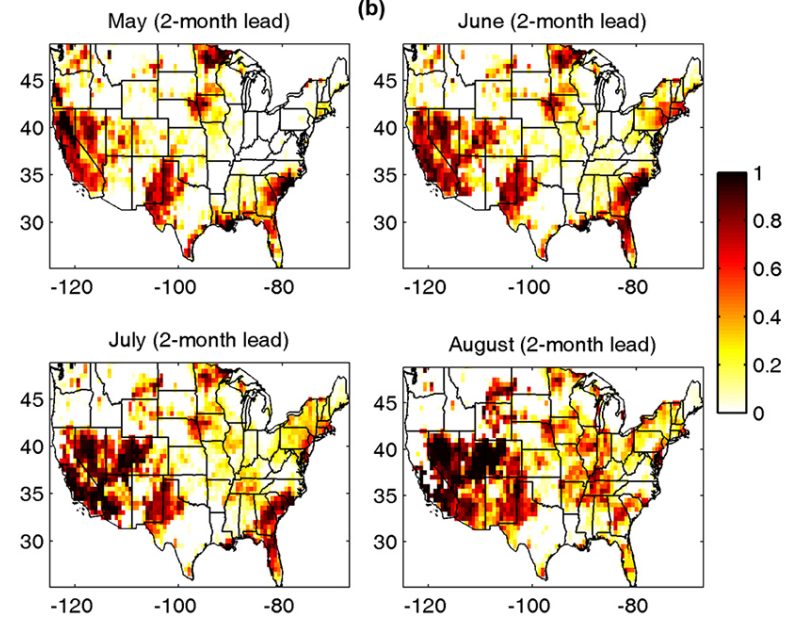

Figure 3. (a) The 1-month and (b) 2-month lead drought probability predictions for May-August 2012 for SSI6 <-0.8.
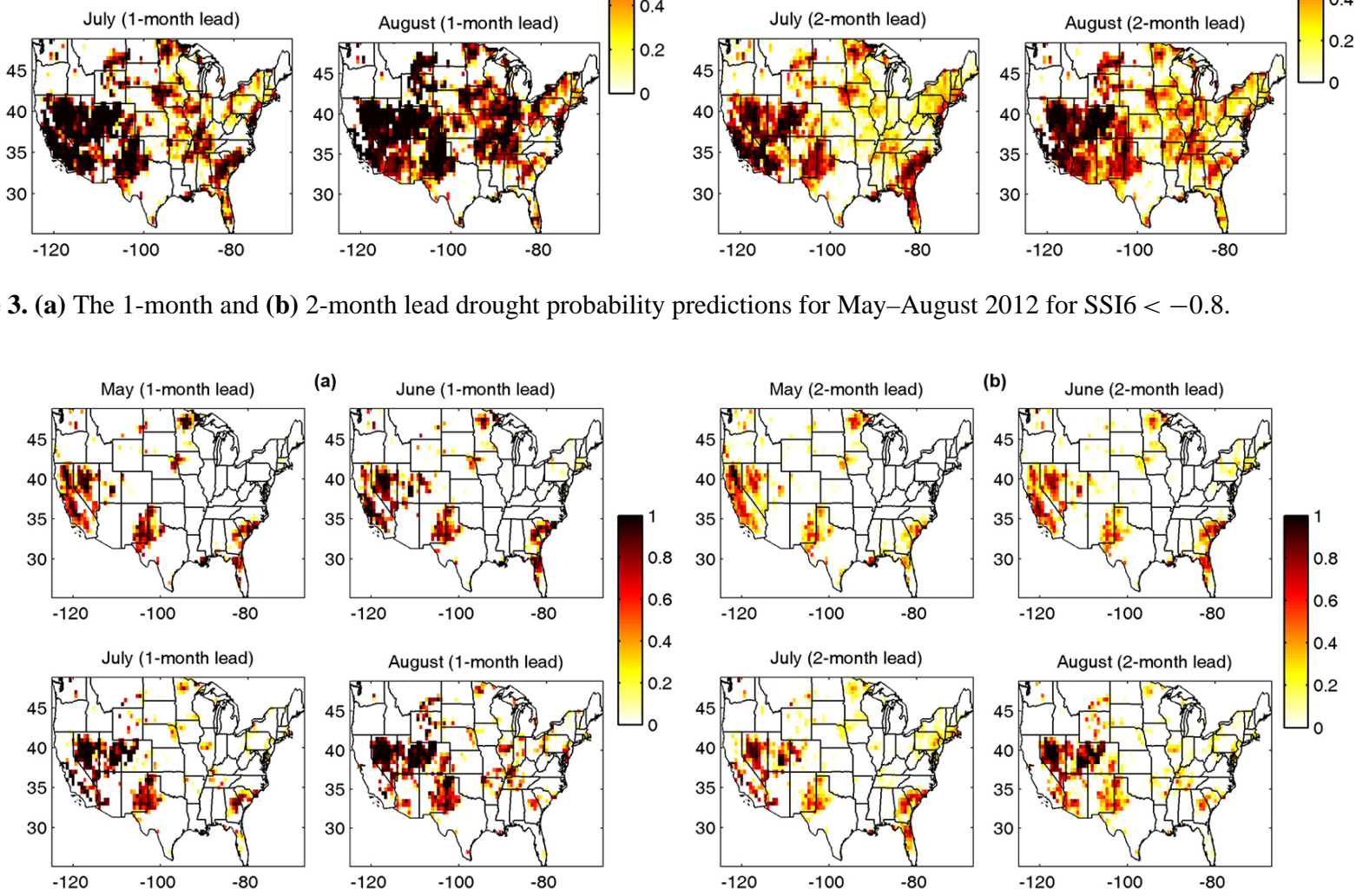

Figure 4. (a) The 1-month and (b) 2-month lead drought probability predictions for May-August 2012 for SSI6 <-1.3.

The prediction skill of the model is higher in the western US where drought conditions are predicted at higher probabilities relative to the Midwest. A review of Figs. 3 and 4 indicates that the predicted probabilities in longer leads (i.e., 3 and 4 months) are typically lower than those of shorter (1 and 2 months) lead forecasts. Basically, in persistence-based models, as the lead month increases, one expects the forecast probabilities to decrease as well. This can be partly explained from the autocorrelations of accumulated soil moisture presented in Fig. 1. As shown, in the western US, the 4-month lead forecasted drought probabilities for July and August 2012 are relatively high and in fairly good agreement with observations. In the Midwest and eastern US, the proposed model indicates relatively low probabilities of drought for 3- and 4-month lead forecasts. While the forecasted drought probabilities are lower at a 4-month lead, still they provide valuable information by showing the drought signal. While the 3- and 4-month lead forecasted probabilities of severe droughts are substantially less compared to the 2-month lead forecasts, the drought signal in the western US is still strong (see Fig. 5b).

It should be noted that the seasonal climate predictions based on weather/climate models initialized in April and May 2012 revealed limited drought information for MayJuly and June-August 2012 (Hoerling et al., 2013). This highlights that improvements in just two 2-month lead forecasts could be very important for risk assessment and decision-making. The presented persistence-based model with the SSI as the drought indicator provides the potential capability to predict droughts that would be of great value to agricultural planning.

The quality and the latency of predictions rely on the quality and availability of input data sets. Currently, limited observations of soil moisture are available across the globe, and soil moisture estimation relies on model simulations. The soil moisture ocean salinity (SMOS; Kerr et al., 2001) and 

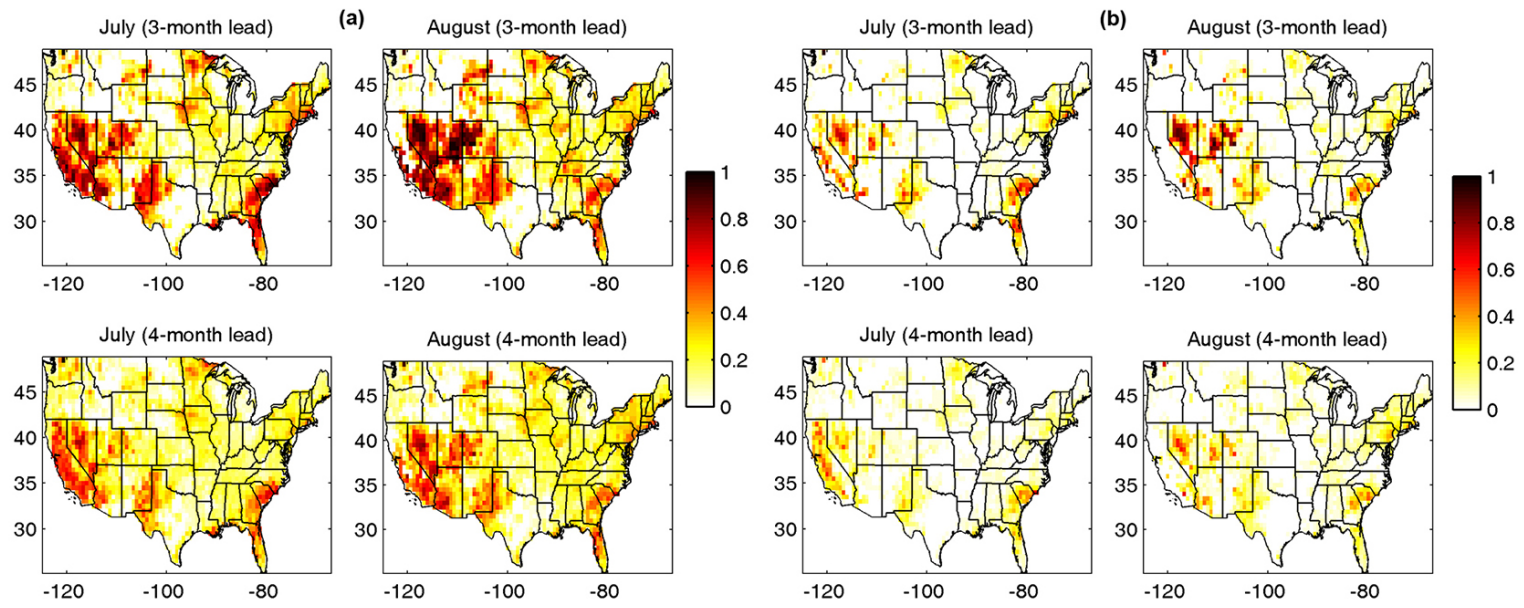

Figure 5. The 3- and 4-month lead time predictions of drought probability for July-August 2012; (a) SSI6 <-0.8; (b) SSI6 < -1.3.

the upcoming soil moisture active and passive (SMAP; Entekhabi et al., 2010) mission may provide the opportunity to integrate near real-time satellite data with long-term climate data records such as MERRA to improve drought monitoring and prediction.

\section{Conclusions}

Using the standardized soil moisture index (SSI) as the drought indicator, a persistence-based drought prediction method is presented and used for predicting the 2012 United States drought. It is shown that because of high persistence property of soil moisture, the SSI can be used for seasonal drought forecasting. The presented statistical approach predicted the May-August drought conditions relatively well, especially for 1- and 2-month lead forecasts. The 3- and 4month lead forecasts of the western US were in good agreement with observations. However, the drought prediction signal in the eastern US was not as strong at 3-and 4-month lead time. Given the persistence-based nature of the methodology, uncertainties of predictions increase with lead time. Similar behavior has been observed in persistence-based drought recovery assessment (Pan et al., 2013). However, even 1- and 2-month lead information is valuable to some end users including farmers and commodity investors.

It is acknowledged that, similar to other methods, both the presented modeling framework and input data sets are subject to uncertainties (e.g., see Quan et al., 2012). The presented model is based on near-past soil moisture conditions and long-term climatology. Soil moisture responds to precipitation with some delay, and for this reason the methodology may not capture rapid developments. Furthermore, this methodology relies on historical observations; because of limited samples of extreme conditions in historical records, it should not be used for predicting extreme droughts.
It is stressed that the proposed approach is not meant to replace the currently available dynamic drought forecasting models. Rather, the persistence-based predictions should be used as additional information that can potentially improve drought predictability. Finally, it should be pointed out that SSI is not suggested as an alternative to using SPI (or other indicators) for seasonal drought prediction. The best choice of index or the best set of indicators depends on the problem at hand and the climate of the study area. It is our view that drought monitoring and prediction should be based on multiple sources of information (data and indicator) as well as models (e.g., dynamic, statistical).

Acknowledgements. The author appreciates the constructive comments and suggestions from three anonymous reviewers that led to substantial improvement in the current version. This study is partially supported by the NOAA Modeling, Analysis, Prediction, and Projections (MAPP) program (award no. NA14OAR4310222), and the Hellman Foundation.

Edited by: F. Pappenberger

\section{References}

AghaKouchak, A. and Nakhjiri, N.: A Near Real-Time SatelliteBased Global Drought Climate Data Record, Environ. Res. Lett., 7, 044037, doi:10.1088/1748-9326/7/4/044037, 2012.

Bosilovich, M. G., Robertson, F. R., and Chen, J.: Global energy and water budgets in MERRA, J. Climate, 24(22), 5721-5739, 2011.

Changnon Jr., S. A.: Detecting drought conditions in Illinois, Illinois State Water Survey, Champaign, IL, USA, ISWS C-169, 36 pp., 1987.

Damberg, L. and AghaKouchak, A.: Global Trends and Patterns of Droughts from Space, Theor. Appl. Climatol., doi:10.1007/s00704-013-1019-5, in press, 2013. 
Day, G. N.: Extended streamflow forecasting using NWSRFS, J. Water Res. Pl.-ASCE, 111, 157-170, 1985.

Dutra, E., Viterbo, P., and Miranda, P. M.: ERA-40 reanalysis hydrological applications in the characterization of regional drought, Geophys. Res. Lett., 35, L19402, doi:10.1029/2008GL035381, 2008.

Dutra, E., Di Giuseppe, F., Wetterhall, F., and Pappenberger, F.: Seasonal forecasts of droughts in African basins using the Standardized Precipitation Index, Hydrol. Earth Syst. Sci., 17, 2359 2373, doi:10.5194/hess-17-2359-2013, 2013.

Dutra, E., Wetterhall, F., Di Giuseppe, F., Naumann, G., Barbosa, P., Vogt, J., Pozzi, W., and Pappenberger, F.: Global meteorological drought - Part 1: Probabilistic monitoring, Hydrol. Earth Syst. Sci. Discuss., 11, 889-917, doi:10.5194/hessd-11889-2014, 2014a.

Dutra, E., Pozzi, W., Wetterhall, F., Di Giuseppe, F., Magnusson, L., Naumann, G., Barbosa, P., Vogt, J., and Pappenberger, F.: Global meteorological drought - Part 2: Seasonal forecasts, Hydrol. Earth Syst. Sci. Discuss., 11, 919-944, doi:10.5194/hessd11-919-2014, 2014b.

Entekhabi, D., Njoku, E. G., O’Neill, P. E., Kellogg, K. H., Crow, W. T., Edelstein, W. N., and Van Zyl, J.: The soil moisture active passive (SMAP) mission, Proceedings of the IEEE, 98, 704-716, 2010.

Entin, J. K., Robock, A., Vinnikov, K. Y., Hollinger, S. E., Liu, S., and Namkhai, A.: Temporal and spatial scales of observed soil moisture variations in the extratropics, J. Geophys. Res., 105, 11865-11877, doi:10.1029/2000JD900051, 2000

Goddard, L., Barnston, A., and Mason, S.: Evaluation of the IRI's "Net assessment" seasonal climate forecasts: 1997-2001, B. Am. Meteorol. Soc., 84, 1761-1781, 2003.

Golian, S., Mazdiyasni, O., and AghaKouchak, A.: Trends in Meteorological and Agricultural Droughts in Iran, Theor. Appl. Climatol., doi:10.1007/s00704-014-1139-6, in press, 2014.

Gringorten, I. I.: A Plotting Rule for Extreme Probability Paper, J. Geophys. Res., 68, 813-814, doi:10.1029/JZ068i003p00813, 1963.

Hao, Z. and AghaKouchak, A.: Multivariate Standardized Drought Index: A multi-Index parametric approach for drought analysis, Adv. Water Resour., 57, 12-18, 2013.

Hao, Z. and AghaKouchak, A.: A Nonparametric Multivariate Multi-Index Drought Monitoring Framework, J. Hydrometeorol., 15, 89-101, doi:10.1175/JHM-D-12-0160.1, 2014.

Hao, Z., AghaKouchak, A., Nakhjiri, N., and Farahmand, A.: Global Integrated Drought Monitoring and Prediction System, Scientific Data, Nature Publishing Group, UK, 1, 140001, doi:10.1038/sdata.2014.1, 2014.

Heim, R. R. A review of twentieth-century drought indices used in the United States, B. Am. Meteorol. Soc., 83, 1149-1166, 2002.

Hoerling, M., Schubert, S., and Mo, K.: An Interpretation of the Origins of the 2012 Central Great Plains Drought, Assessment Report, NOAA Drought Task Force, USA, 2013.

Hoerling, M., Eischeid, J., Kumar, A., Leung, R., Mariotti, A., Mo, K., Schubert, S., and Seager, R.: Causes and predictability of the 2012 Great Plains drought, B. Am. Meteorol. Soc., 95, 269-282, 2014.

Kennedy, A. D., Dong, X., Xi, B., Xie, S., Zhang, Y., and Chen, J.: A comparison of MERRA and NARR reanalyses with the DOE ARM SGP data, J. Climate, 24, 4541-4557, 2011.
Kerr, Y. H., Waldteufel, P., Wigneron, J. P., Martinuzzi, J., Font, J., and Berger, M.: Soil moisture retrieval from space: The Soil Moisture and Ocean Salinity (SMOS) mission, IEEE T. Geosci. Remote, 39, 1729-1735, 2001.

Koster, R. D., Mahanama, S. P. P., Yamada, T. J., Balsamo, G., Berg, A. A., Boisserie, M., Dirmeyer, P. A., Doblas-Reyes, F. J., Drewitt, G., Gordon, C. T., Guo, Z., Jeong, J.-H., Lawrence, D. M., Lee, W.-S., Li, Z., Luo, L., Malyshev, S., Merryfield, W. J., Seneviratne, S. I., Stanelle, T., van den Hurk, B. J. J. M., Vitart, F., and Wood, E. F.: Contribution of land surface initialization to subseasonal forecast skill: First results from a multi-model experiment, Geophys. Res. Lett., 37, L02402, doi:10.1029/2009GL041677, 2010.

Lavers, D., L. Luo, L., and Wood, E. F.: A multiple model assessment of seasonal climate forecast skill for applications, Geophys. Res. Lett., 36, L23711, doi:10.1029/2009GL041365, 2009.

Li, H., Luo, L. and Wood, E. F.: Seasonal hydrologic predictions of low-flow conditions over eastern USA during the 2007 drought, Atmos. Sci. Lett., 9, 61-66, 2008.

Livezey, R. E. and Timofeyeva, M. M.: The first decade of longlead US seasonal forecasts: Insights from a skill analysis, B. Am. Meteorol. Soc., 89, 843-854, 2008.

Luo, L. and Wood, E. F.: Monitoring and predicting the 2007 US drought, Geophys. Res. Lett., 34, L22702, doi:10.1029/2007GL031673, 2007.

Luo, L. and Wood, E. F.: Use of Bayesian merging techniques in a multimodel seasonal hydrologic ensemble prediction system for the eastern United States, J. Hydrometeorol., 9, 866-884, 2008.

Lyon, B., Bell, M. A., Tippett, M. K., Kumar, A., Hoerling, M. P., Quan, X.-W., and Wang, H.: Baseline probabilities for the seasonal prediction of meteorological drought, J. Appl. Meteorol. Clim., 51, 1222-1237, 2012.

Madadgar, S. and Moradkhani, H.: A Bayesian Framework for Probabilistic Seasonal Drought Forecasting, J. Hydrometeorol., 14, 1685-1705, doi:10.1175/JHM-D-13-010.1, 2013.

McKee, T. B., Doesken, N. J., and Kleist, J.: The relationship of drought frequency and duration to time scales, Eighth Conference on Applied Climatology, Am. Meteorol. Soc., Anaheim, CA, USA, 1993.

Mishra, A. K. and Singh, V. P.: A review of drought concepts, J. Hydrol., 391, 202-216, 2010.

Mishra, A. K., Singh, V. P., and Desai, V. R.: Drought characterization: a probabilistic approach, Stoch. Env. Res. Risk A., 23, 41-55, 2009.

Mwangi, E., Wetterhall, F., Dutra, E., Di Giuseppe, F., and Pappenberger, F.: Forecasting droughts in East Africa, Hydrol. Earth Syst. Sci., 18, 611-620, doi:10.5194/hess-18-611-2014, 2014.

Mo, K. C.: Model-Based Drought Indices over the United States, J. Hydrometeorol., 9, 1212-1230, 2008.

Mo, K. C., Shukla, S., Lettenmaier, D. P., and Chen, L.-C.: Do Climate Forecast System (CFSv2) forecasts improve seasonal soil moisture prediction?, Geophys, Res. Lett., 39, L23703, doi:10.1029/2012GL053598, 2012.

National Research Council: Completing the Forecast: Characterizing and Communicating Uncertainty for Better Decisions Using Weather and Climate Forecasts, The National Academies Press, Washington, D.C., USA, 2006. 
Pan, M., Yuan, X., and Wood, E. F.: A probabilistic framework for assessing drought recovery, Geophys. Res. Lett., 40, 3637-3642, 2013.

Pozzi, W., Sheffield, J., Stefanski, R., Cripe, D., Pulwarty, R., Vogt, J. V., Heim Jr., R. R., Brewer, M. J., Svoboda, M., Westerhoff, R., Van Dijk, A. I. J. M., Lloyd-Hughes, B., Pappenberger, F., Werner, M., Dutra, E., Wetterhall, F., Wagner, W., Schubert, S., Mo, K., and Nicholson, M.: Toward global drought early warning capability, B. Am. Meteorol. Soc., 94, 776-787, doi:10.1175/BAMS-D-11-00176.1, 2013.

Quan, X.-W., Hoerling, M. P., Lyon, B., Kumar, A., Bell, M. A., Tippett, M. K., and Wang, H.: Prospects for dynamical prediction of meteorological drought, J. Appl. Meteorol. Clim., 51, 12381252, 2012.

Reichle, R. H., Koster, R. D., De Lannoy, G. J. M., Forman, B. A., Liu, Q., Mahanama, S. P. P., and Touré, A.: Assessment and enhancement of MERRA land surface hydrology estimates, J. Climate, 24, 6322-6338, 2011.

Rienecker, M. M., Suarez, M. J., Gelaro, R., Todling, R., Bacmeister, J., Liu, E., Bosilovich, M. G., Schubert, S. D., Takacs, L., Kim, G.-K., Bloom, S., Chen, J., Collins, D., Conaty, A., da Silva, A., Gu, W., Joiner, J., Koster, R. D., Lucchesi, R., Molod, A., Owens, T., Pawson, S., Pegion, P., Redder, C. R., Reichle, R., Robertson, F. R., Ruddick, A. G., Sienkiewicz, M., and Woollen, J.: MERRA: NASA's modern-era retrospective analysis for research and applications, J. Climate, 24, 3624-3648, 2011.

Samaniego, L., Kumar, R., and Zink, M.: Implications of parameter uncertainty on soil moisture drought analysis in Germany, J. Hydrometeorol., 14, 47-68, 2013.

Seneviratne, S. I., Koster, R. D., Guo, Z., Dirmeyer, P. A., Kowalczyk, E., Lawrence, D., Liu, P., Lu, C.-H., Mocko, D., Oleson, K. W., and Verseghy, D.: Soil moisture memory in AGCM simulations: analysis of global land-atmosphere coupling experiment (GLACE) data, J. Hydrometeorol., 7, 1090-1112, 2006.

Sheffield, J. and Wood, E. F.: Characteristics of global and regional drought, 1950-2000: Analysis of soil moisture data from off-line simulation of the terrestrial hydrologic cycle, J. Geophys. Res., 112, D17115, doi:10.1029/2006JD008288, 2007.

Sheffield, J. and Wood, E. F.: Global trends and variability in soil moisture and drought characteristics, 1950-2000, from observation-driven simulations of the terrestrial hydrologic cycle, J. Climate, 21, 432-458, 2008.

Sheffield, J., Wood, E. F., Lettenmaier, D., and Lipponen, A.: Experimental drought monitoring for Africa, GEWEX News, 18, 4-6, 2008.

Shukla, S. and Lettenmaier, D. P.: Seasonal hydrologic prediction in the United States: understanding the role of initial hydrologic conditions and seasonal climate forecast skill, Hydrol. Earth Syst. Sci. Discuss., 8, 6565-6592, doi:10.5194/hessd-86565-2011, 2011.
Shukla, S., Steinemann, A. C., and Lettenmaier, D. P.: Drought Monitoring for Washington State: Indicators and Applications, J. Hydrometeorol., 12, 66-83, 2011.

Steinemann, A. C.: Using climate forecasts for drought management, J. Appl. Meteorol. Clim., 45, 1353-1361, 2006.

Svoboda, M., Lecomte, D., Hayes, M., Heim, R., Gleason, K., Angel, J., Rippey, B., Tinker, R., Palecki, M., Stooksbury, D., Miskus, D., and Stephens, S.: The drought monitor, B. Am. Meteorol. Soc., 83, 1181-1190, 2002.

Trambauer, P., Maskey, S., Winsemius, H., Werner, M., and Uhlenbrook, S.: A review of continental scale hydrological models and their suitability for drought forecasting in (sub-Saharan) Africa, Phys. Chem. Earth Pt. A/B/C, 66, 16-26, 2013.

Twedt, T. M., Schaake Jr., J. C., and Peck, E. L., National Weather Service extended streamflow prediction, in: Proc. 45th Western Snow Conference, Albuquerque, NM, Colorado State University, USA, 52-57, 1977.

USDA: U.S. Drought 2012: Farm and Food Impacts, available at: http://www.ers.usda.gov/topics/in-the-news/ us-drought-2012-farm-and-food-impacts.aspx, last access: 9 February 2014, 2012.

Vinnikov, K. Y. and Yeserkepova, I.: Soil moisture: Empirical data and model results, J. Climate, 4, 66-79, 1991.

WCRP: WCRP White Paper on "Drought Predictability and Prediction in a Changing Climate: Assessing Current Capabilities", User Requirements, and Research Priorities, Tech. rep., World Climate Research Programme, Barcelona, Spain, 2010.

Wong, S., Fetzer, E. J., Kahn, B. H., Tian, B., Lambrigtsen, B. H., and Ye, H.: Closing the Global Water Vapor Budget with AIRS Water Vapor, MERRA Reanalysis, TRMM and GPCP Precipitation, and GSSTF Surface Evaporation, J. Climate, 24, 63076321, 2011.

Wood, A. W.: The University of Washington Surface Water Monitor: An experimental platform for national hydrologic assessment and prediction. American Meteorology Society Annual Meeting, 22nd Conference on Hydrology, New Orleans, USA, 2008.

Wood, A. W. and Lettenmaier, D. P.: A test bed for new seasonal hydrologic forecasting approaches in the western United States, B. Am. Meteorol. Soc., 87, 1699-1712, 2006.

Wood, A. W., Maurer, E. P., Kumar, A., and Lettenmaier, D. P.: Long-range experimental hydrologic forecasting for the eastern United States. J. Geophys. Res., 107, 4429, doi:10.1029/2001JD000659, 2002.

Yi, Y., Kimball, J. S., Jones L. A., Reichle, R. H., and McDonald, K. C.: Evaluation of MERRA land surface estimates in preparation for the Soil Moisture Active Passive Mission, J. Climate, 24, 3797-3816, 2011.

Yoon, J. H., Mo, K., and Wood, E. F.: Dynamic-Model-Based Seasonal Prediction of Meteorological Drought over the Contiguous United States, J. Hydrometeorol., 13, 463-482, 2012. 